\title{
Pengaruh Media Pembelajaran Adobe Flash Terhadap Komunikasi Matematis Siswa SMPN 8 Langsa
}

\author{
${ }^{1}$ Srimuliati, ${ }^{2}$ Nurlaila Fazrani \\ 1,2 Institut Agama Islam Negeri (IAIN) Langsa, Aceh \\ E-mail:srimuliati@iainlangsa.ac.id,nurlailafazrani11@gmail.com
}

\section{Article Info \\ Article History \\ Received: 2021-03-12 \\ Revised: 2021-04-20 \\ Published: 2021-06-02}

Keywords:

Adobe Flash;

Mathematical

Communication.
Mathematica;

\begin{abstract}
Mathematical communication is one of the important components in learning mathematics, this is because with mathematical communication skills students can convey ideas or ideas that are right to others, both orally and in writing. In fact, teachers need learning strategies that can improve students' mathematical communication skills. Adobe flash is a learning medium that can improve students' mathematical communication skills. This study aims to determine the effect of using adobe flash on students' mathematical communication abilities. The population in this study were 103 students of class VII SMP N 8 Langsa in the academic year 2019/2020. The sample in this study was taken by using random sampling technique. Class VII. 2 as a control group of 20 students and as many as 19 students in class VII.1 as the experimental group. This study used a quasi experimental design with a pretest and posttest design. Hypothesis testing uses the Mann Whitney Sample U Test because the data is not normally distributed. The test results using the Mann Whitney Sample U Test show that $\mathrm{Sig}<\alpha$ or $0.003<0.05$ means that there is a significant effect of using adobe flash learning media on students' mathematical communication skills between the control and experimental classes. It is concluded that the use of Adobe Flash learning media affects the mathematical communication of students of SMP N 8 Langsa.
\end{abstract}

\begin{tabular}{l}
\hline Artikel Info \\
\hline Sejarah Artikel \\
Diterima: 2021-03-12 \\
Direvisi: 2021-04-20 \\
Dipublikasi: 2021-06-02
\end{tabular}

Kata kunci:

Matematika; Adobe Flash;

Komunikasi Matematis.

\begin{abstract}
Abstrak
Komunikasi matematis merupakan salah satu komponen penting dalam pembelajaran matematika, hal ini karena dengan kemampuan komunikasi matematis siswa dapat menyampaikan ide atau gagasan yang tepat kepada orang lain baik secara lisan maupun tulisan. Kenyataannya, pengajar membutuhkan strategi pembelajaran yang dapat meningkatkan kemampuan komunikasi matematis siswa. Adobe flash merupakan media pembelajaran yang dapat meningkatkan kemampuan komunikasi matematis siswa. Penelitian ini bertujuan untuk mengetahui pengaruh penggunaan adobe flash terhadap kemampuan komunikasi matematis siswa. Populasi dalam penelitian ini yaitu siswa kelas VII SMP N 8 Langsa tahun ajaran 2019/ 2020 yang berjumlah 103 siswa. Sampel penelitian ini diambil dengan teknik sample random sampling. Kelas VII. 2 sebagai kelompok kontrol sebanyak 20 siswa dan sebanyak 19 siswa pada kelas VII.1 sebagai kelompok eksperimen. Penelitian ini menggunakan desain quasi experimental dengan bentuk pretest and posttest design. Pengujian hipotesis menggunakan uji Mann Whitney Sample U Test hal ini karena data berdistribusi tidak normal. Hasil uji menggunakan Mann Whitney Sample U Test menunjukkan bahwa Sig $<\alpha$ atau 0,003 $<0,05$ artinya terdapat pengaruh penggunaan media pembelajaran adobe flash terhadap kemampuan komunikasi matematis siswa yang signifikan antara kelas kontrol dan eksperimen. Disimpulkan bahwa penggunaan media pembelajaran adobe flash berpengaruh terhadap komunikasi matematis siswa SMP N 8 Langsa.
\end{abstract}

\section{PENDAHULUAN}

Matematika merupakan salah satu ilmu yang diajarkan pada setiap tingkat jenjang pendidikan. Diajarkannya matematika tentu memiliki tujuan tersendiri bagi dunia pendidikan maupun bagi pelajar itu sendiri. Tujuan pembelajaran matematika di Indonesia termuat dalam Standar Isi yang mana agar peserta didik memiliki kemampuan, a) Memahami konsep matematika, menjelaskan keterkaitan antar konsep dan mengaplikasikan konsep atau algoritma, secara luwes, akurat, efisien, dan tepat, dalam pemecahan masalah. b) Menggunakan penalaran pada pola dan sifat, melakukan manipulasi matematika dalam membuat generalisasi, menyusun bukti, atau menjelaskan gagasan dan pernyataan matematika, c) Memecahkan masalah yang meliputi kemampuan memahami masalah, merancang model matematika, menyelesaikan model dan manafsirkan solusi yang 
diperboleh, d) Mengkomunikasikan gagasan dengan simbol, tabel, diagram, atau media lain untuk memperjelas keadaan atau masalah, e) Memiliki sikap menghargai kegunaan matematika dalam kehidupan, yaitu memiliki rasa ingin tahu, perhatian, dan minat dalam mempelajari matematika, serta sikap ulet dan percaya diri dalam pemecahan masalah.

Berdasarkan tujuan pembelajaran matematika di atas. kemampuan komunikasi merupakan salah satu poin penting yang harus diperhatikan dalam dunia pendidikan. Dalam dunia pendidikan, Indonesia menjadikan PISA sebagai acuan dalam meningkatkan kualitas Indonesia. Namun, peringkat Indonesia semakin menurun sejak terdaftarnya Indonesia pada tahun 2000, dalam hasil studi PISA (Programme for International Student Assesment) seperti disebut Tohir (2019) bahwa peringkat PISA Indonesia tahun 2018 turun apabila dibandingkan dengan hasil PISA tahun 2015. Studi pada tahun 2018 ini menilai 600.000 anak berusia 15 tahun dari 79 negara. Dalam kategori matematika Indonesia berada di peringkat 7 dari bawah alias peringkat 73 dengan skor rata-rata 379. Indonesia berada diatas Arab Saudi yang memiliki skor rata-rata 373 . Sementara peringkat satu, masih diduduki China dengan skor rata-rata 591 (Tohir, 2019). Salah satu faktor penyebab menurunya hasil PISA adalah soal yang diujikan pada tes tersebut. Dalam menjawab pertanyaan-pertanyaan PISA siswa harus mampu menganalisis, bernalar, dan mengkomunikasikan pengetahuan dan keterampilan matematikanya secara efektif, serta mampu memcahkan dan menginterpretasikan penyelesaian masalah matematika dalam berbagai situasi.

Dilihat dari hal di atas, kemampuan dalam mengkomunikasikan matematika merupakan salah satu komponen penting dalam pembelajaran matematika. Namun, kenyataannya banyak siswa mampu dalam berbagai hitungan matematika namun lemah dalam mengkomunikasikan berbagai lambang dan simbol matematika. Padahal Suryadi (dalam Yeni, 2014) mengatakan komunikasi matematika adalah cara untuk berbagi ide dan memperjelas pemahaman pada belajar matematika. Yeni Yunarti (2014) juga mengatakan bahwa melalui komunikasi, ide matematika dapat dieksploitasi dalam berbagai perspektif; cara berpikir siswa dapat dipertajam; pertumbuhan pemahaman dapat diukur; pemikiran siswa dapat dikonsolidasikan dan diorganisir; pengetahuan matematika dan pengembangan masalah siswa dapat ditingkatkan; dan komunikasi matematis dapat dibentuk sesuai dengan tingkatan atau jenjang pendidikan sehingga tingkat kemampuan komunikasi matematika menjadi beragam. Oleh karena itu, kemampuan komunikasi siswa sangat penting sebagai alat untuk menyampaikan idea tau gagasan dengan tepat. Jika kemampuan komunikasi matematis lemah, maka pemahaman yang akan diajarkan kepada orang lain juga akan berkurang. Maka dari itu perlu upaya yang tepat untuk meningkatkan kemampuan komunikasi matematis siswa, salah satu upaya yang dapat dilakukan adalah dengan menggunakan media pembelajaran saat kegiatan belajar mengajar berlangsung.

Komunikasi matematis merupakan suatu kemampuan dalam matematika yang harus dimiliki siswa. Komunikasi matematis dapat diartikan sebagai suatu peristiwa saling hubungan/dialog yang terjadi dalam suatu lingkungan kelas, dimana terjadi pengalihan pesan (Darkasyi, 2014). Suhendra mendefinisikan kemampuan komunikasi matematis adalah suatu kemampuan untuk mengungkapkan ide atau gagasan matematis dengan bahasa sendiri (Pane, 2018). Jadi, dengan menggunakan bahasa matematika yang benar untuk berbicara dan menulis tentang apa yang mereka kerjakan, mereka akan mampu mengklarifikasi ide-ide mereka dan belajar bagaimana berpendapat dengan meyakinkan dan mempresentasikan ide-ide matematika mereka sendiri.

Untuk mengetahui mampu tidaknya siswa dalam berkomunikas matematis dapat diukur melalui beberapa indikator. Indikator matematika ini merupakan aspek-aspek penting agar siswa mencapai sasaran pada soal matematika sehingga target yang diinginkan dalam berkomunikasi matematika terwujud. Adapun indikator komunikasi matematis yaitu (1) mampu mengekspresikan ide-ide matematis baik melalui tulisan, lisan, dan menggambarkan secara visual; (2) mampu memahami, menginterpretasikan, dan mengevaluasi ide-ide matematis secara lisan, tulisan maupun dalam bentuk visual lainnya; dan (3) mampu dalam menggunakan istilah-istilah, notasinotasi matematika dan struktur-strukturnya untuk menyajikan ide-ide, menggambarkan hubunganhubungan dengan model-model situasi (Sumarmo dalam Darkasyi, 2014; NCTM dalam Pane, 2018).

Pentingnya kemampuan komunikasi bagi siswa menjadikan kemampuan ini harus dilatihkan agar dapat berkembang. Saat ini, dimana teknologi dan informasi mulai berkembang pesat, media pembelajaran sendiri juga mulai mengalami banyak perkembangan, contohnya yaitu media pembelajaran berbasis multimedia. Hasil penelitian BAVA di Amerika Serikat menegaskan bahwa bila seorang guru atau tenaga pendidik yang mengajar hanya menggunakan verbal sImbol (ceramah murni), maka materi yang terserap hanya $13 \%$ dan itu pun tidak akan bertahan lama, sementara yang menggunakan multimedia bisa mencapai 64 sampai $84 \%$ dan bertahan lama. Hal ini menunjukkan bahwa penggunaan media pembelajaran memberikan dampak yang besar bagi kemauan siswa dalam mengikuti proses pembelajaran sehingga dapat meningkatkan kemampuan komunikasi matematis siswa.

Salah satu media pembelajaran berbasis mulitimedia yang dapat digunakan yaitu berupa adobe flash yang merupakan aplikasi software komputer yang berfungsi dalam mendesain gambar maupun video animasi. Supriadi mengemukakan bahwa adobe flash adalah aplikasi yang dipakai luas oleh para profesional web karena kemampuannya 
yang mengagumkan dalam menampilkan multimedia, menggabungkan unsur teks, grafis, animasi, suara dan serta interaktivitas bagi pengguna.

Hasil wawancara dengan pengajar di SMP N 8 Langsa diketahui bahwa sebagian d siswa tidak tertarik atau bersemangat dalam belajar matematika. Selain karena faktor eksternal pada diri siswa, faktor internal lebih mendominasi. Hal ini diketahui dari beberapa siswa yang cenderung tidak peduli dengan belajarnya karena faktor ekonomi keluarga. Ada juga yang acuh saat belajar karena merasa tidak tertarik dan butuh dengan matematika. Ini menjadi tugas berat untuk mengubahnya. Maka dari itu sebagai salah satu solusi, dibutuhkan media pembelajaran yang dapat menarik perhatian minat siswa dalam belajar. Adobe flash merupakan salah satu media interaktif yang bisa digunakan dalam kegiatan pembelajaran di SMP N 8 Langsa. Dengan adanya beberapa unsur seperti, animasi, suara, serta grafis yang bagus adobe flash bisa menarik perhatian siswa dalam belajar. berdasarkan hal tersebut, setidaknya dengan menggunakan media pembelajaran adobe flash siswa bisa memiliki pengalaman belajar yang lebih menarik serta dapat memahami komunikasi matematis menjadi lebih baik. Nina (Unaisyah, 2018) menjelaskan bahwa adobe flash memiliki beberapa kelebihan sehingga memilih adobe flash untuk mengembangkan media pembelajaran. Kelebihankelebihan yang dimiliki adobe flash diantaranya yaitu: (1) Hasil akhir file flash setelah dipublish memiliki ukuran yang lebih kecil; (2) Flash memiliki kemampuan mengimpor dan mengolah jenis file mulai dari file gambar, video dan audio sehingga memungkinkan hasil sajian materi menggunakan adobe flash menjadi lebih menarik dan hidup; dan (3) Animasi dapat dibuat dan dijalankan sesuai kebutuhan. Hasil file flash yang dapat berupa file "*.exe" (executable) memungkinkankan untuk menjalankan file flash pada PC tanpa harus terlebih dahulu menginstal program adobe flash.

Adobe flash terdiri dari beberapa tipe, dimana setiap tipenya merupakan penyempurnaan dari tipe sebelumnya. Pada penelitian ini digunakan adobe flash CS6 yang merupakan penyempurnaan dari jenis adobe flash CS5. Berdasarkan uraian di atas, tulisan ini berfokus pada pengaruh penggunaan media adobe flash terhadap komunikasi matematis siswa.

\section{METODE PENELITIAN}

Rancangan penelitian menggunakan quasi experimental (eksperimen semu) dengan bentuk pretest and posttest design. Penelitian ini menggunakan dua kelas yaitu kelas eksperimen dan kelas kontrol dengan menggunakan tes awal dan tes akhir sebagai evaluasi dalam penelitian ini. Penelitian ini dilakukan pada siswa kelas VII. Instrumen yang digunakan untuk penelitian berupa tes komunikasi matematis bentuk uraian. Pemberian tes dilakukan dua kali, yaitu saat pretest dan posttest. Data hasil tes kemampuan komunikasi matematis dianalisis menggunakan uji mann withney u-test dengan kriteria pengujian $\mathrm{H}_{0}$ diterima apabila $\operatorname{sig}>0,05$ dan $\mathrm{H}_{0}$ ditolak apabila sig $<0,05$.

1. Populasi dan Sampel Penelitian

Populasi dalam penelitian ini adalah seluruh siswa kelas VII yang berjumlah 103 siswa. Pengambilan sampel dalam penelitian ini menggunakan tehnik simple random sampling. Simple random sampling merupakan pengambilan anggota sample dari populasi yang dilakukan secara acak tanpa memperhatikan strata yang ada didalam populasi tersebut (Sugiyono, 2010), Pengambilan sampel dilakukan secara acak dengan mengambil 2 kelas sebagai kelas eksperimen dan kelas kontrol, maka dipilih kelas VII.1 sebagai kelas eksperimen dan kelas VII.2 Sebagai kelas kontrol. Kelompok eksperimen diberikan pembelajaran menggunakan media pembelajaran adobe flash, sedangkan kelas kontrol diberikan pembelajaran tanpa menggunakan media pembelajaran adobe flash.

2. Variabel Penelitian

Penelitian ini dilaksanakan di SMP Negeri 8 Langsa. Adapun variabel-variabel yang terdapat pada penelitian ini yaitu variabel bebas : media pembelajaran adobe flash dan variabel terikat : kemampuan komunikasi matematis.

\section{Teknik Pengumpulan Data}

Teknik pengumpulan data yang digunakan dalam penelitian ini adalah tes kemampuan komunikasi matematis. Tes berbentuk uraian sebanyak 5 soal diberikan untuk mengetahui bagaimana hasil kemampuna komunikasi matematis siswa.

4. Teknik Analisis Data

Analisis data dalam penelitian ini menggunakan analisis kuantitatif.

Analisis kuantitatif, digunakan untuk menganalisis data yang diperoleh dari hasil tes kemampuan komunikasi matematis siswa. Data di analisis secara kuantitatif dengan menggunakan program SPSS 18.0, Adapun hipotesis statistik yang akan diuji dalam penelitian ini adalah:

$H_{0}: \mu_{1}=\mu_{2}$ Tidak terdapat pengaruh media pembelajaran adobe flash terhadap kemampuan komunikasi matematis siswa di SMP Negeri 8 Langsa.

$H_{a}: \mu_{1} \neq \mu_{2}$ Terdapat pengaruh media pembelajaran adobe flash terhadap kemampuan komunikasi matematis siswa di SMP Negeri 8 Langsa.

Ketentuan uji normalitas data dilakukan melalui perhitungan dengan menggunakan metode Kolmogorov-Smirnov. Apabila data yang diperoleh tidak berdistribusi normal maka kita dapat menganalisis data pada penelitian ini dengan menggunakan analisis non parametrik dengan uji Mann Whitney U-Test. Uji normalitas dilakukan 
untuk mengetahui apakah data berdistribusi normal atau tidak. Uji normalitas dilakukan menggunakan software SPSS 18.0

Uji homogenitas dilakukan untuk membuktikan data dasar yang akan diolah adalah homogen serta untuk mengetahui apakah sampel berasal dari populasi yang sama atau tidak. Uji homogenitas dilakukan menggunakan SPSS 18.0

Uji Mann Whitney U-Test merupakan pengujian non parametrik untuk data yang tidak berdistribusi normal. Tujuan dari pengujian Mann Whitney U-Test ialah untuk pengujian hipotesis pada penelitian ini.

\section{HASIL DAN PEMBAHASAN}

\section{A. Hasil Penelitian}

Berdasarkan hasil penelitian dan analisis data penelitian diperoleh: Hasil penelitian ini bertujuan untuk mengetahui apakah terdapat pengaruh penggunaan media adobe flash terhadap komunikasi matematis siswa di SMPN 8 Langsa. Uji normalitas data dalam penelitian ini menggunakan uji Shapiro-Wilk. Adapun hasil uji normalitas posttest kemampuan komunikasi matematis kelas eksperimen dan kontrol sebagai berikut:

Tabel 1. Hasil Uji Normalitas Data Posttest Tests of Normality

\begin{tabular}{|l|r|r|r|r|r|r|}
\hline & \multicolumn{3}{|c|}{ Kolmogorov-Smirnova } & \multicolumn{3}{|c|}{ Shapiro-Wilk } \\
\cline { 2 - 7 } & Statistic & Df & Sig. & Statistic & df & Sig. \\
\hline $\begin{array}{l}\text { posttest_k } \\
\text { ontrol } \\
\begin{array}{l}\text { posttest_e } \\
\text { ks }\end{array}\end{array}$ & .349 & 19 & .000 & .756 & 19 & .000 \\
\hline
\end{tabular}

a. Lilliefors Significance Correction

Berdasarkan tabel 1. diatas, hasil perhitungan uji normalitas posttest dengan berbantuan SPSS 18.0 dapat dilihat bahwa pada kelas eksperimen nilai sig. $=0,000$ dan pada kelas kontrol nilai sig. $=$ 0,000. Maka dapat disimpulkan bahwa pada data tersebut nilai sig. $<0,05$ maka artinya data tersebut berdistribusi tidak normal. Sehingga untuk mengetahui dengan pasti apakah ada pengaruh penggunaan media pembelajaran adobe flash terhadap kemampuan komunikasi matematis siswa akan dihitung menggunakan analisis non parametrik dengan uji mann whitney u-test.

Tabel 2. Hasil Uji Homogenitas

Test of Homogeneity of Variances Posttest

\begin{tabular}{|c|c|c|c|}
\hline $\begin{array}{c}\text { Levene } \\
\text { Statistic }\end{array}$ & df1 & df2 & Sig. \\
\hline .027 & 1 & 35 & .869 \\
\hline
\end{tabular}

Dari tabel diatas, diperoleh nilai sig. $=0,869$ yang artinya $\operatorname{sig}>0,05$, maka dapat disimpulkan variansi dari kedua kelompok adalah homogen.

Kesimpulan yang dapat diambil dari pengujian normalitas dan homogenitas adalah data berdistribusi tidak normal dan memiliki varians yang sama (homogen), maka pengujian dapat dilanjutkan dengan menggunakan uji non parametrik mann whitney $u$ test.

Untuk mengetahui apakah ada pengaruh penggunaan media pembelajaran adobe flash terhadap kemampuan komunikasi matematis siswa di SMP N 8 Langsa, maka dilakukan uji hipotesis dengan menggunakan uji mann withney $u$-test. Hasil perhitungan pengujian hipotesis disajikan pada tabel berikut:

Tabel 3. hasil uji Mann Whitney Test

Test Statistics ${ }^{b}$

\begin{tabular}{|l|r|}
\hline & \multicolumn{1}{|c|}{ Hasil pretest } \\
\hline Mann-Whitney U & 86.000 \\
Wilcoxon W & 296.000 \\
Z & -3.008 \\
Asymp. Sig. (2-tailed) & .003 \\
Exact Sig. [2*(1-tailed & $.003^{\mathrm{a}}$ \\
Sig.)] & \\
\hline
\end{tabular}

a. Not corrected for ties.

b. Grouping Variable: Kelas

Dari pengujian Mann Whitney $U$ test diperoleh nilai sig. $=0,003$ yang artinya sig $<0,05$, sehingga dapat disimpulkan bahwa $\mathrm{H}_{0}$ ditolak dan $\mathrm{Ha}$ diterima atau terdapat pengaruh penggunaan media pembelajaran adobe flash terhadap kemampuan komunikasi matematis siswa di SMP N 8 Langsa.

\section{B. Pembahasan}

Hasil Penelitian ini bertujuan untuk mengetahui apakah terdapat pengaruh media pembelajaran adobe flash terhadap kemampuan komunikasi matematis siswa di SMP Negeri 8 Langsa. Penelitian ini dilakukan dengan cara memberikan perlakuan (pembelajaran menggunakan media adobe flash) pada salah satu dari dua kelas yang dijadikan sampel penelitian. Untuk melihat ada tidaknya pengaruh pembelajaran dengan menggunakan adobe flash, maka peneliti memberikan tes awal (pretest) dan tes akhir (posttest) pada masing-masing kelas yaitu kelas eksperimen dan kelas kontrol.

Berdasarkan hasil uji data yang telah dilakukan sebelumnya menunjukkan bahwa terdapat perbedaan terhadap hasil belajar matematika siswa pada kelas eksperimen dan kelas kontrol. Dimana dapat diperoleh nilai rata-rata kelas eksperimen untuk pretest sebesar 43,16 sedangkan untuk postest sebesar 75,84 lebih tinggi dari nilai rata-rata sebelumnya. Pada kelas kontrol nilai rata-rata yang diperoleh untuk pretest sebesar 27,11 sedangkan untuk rata-rata nilai postest sebesar 58,68 lebih tinggi dari nilai ratarata sebelumnya. Berdasarkan hasil pengujian 
hipotesis menggunakan uji Mann Whitney Test pada taraf signifikan a $=0,05$ juga diproleh nilai sig. < 0,05 sehingga berdasarkan kriteria pengujian $\mathrm{H}_{\mathrm{o}}$ ditolak dan $\mathrm{H}_{\mathrm{a}}$ diterima. Maka dapat disimpulkan bahwa terdapat pengaruh media pembelajaran media pembelajaran adobe flash terhadap kemampuan komunikasi matematis siswa di SMP Negeri 8 Langsa.

Hasil hipotesis ini didukung oleh pendapat Zahwa dan Fibri yang mengatakan bahwa pembelajaran menggunakan multimedia macromedia flash berpengaruh terhadap hasil belajar matematika dan lebih baik digunakan dalam proses pembelajaran dibandingkan model pembelajaran konvensional.

Pembelajaran dengan menggunakan media adobe flash pada pokok bahasan bangun datar pada penelitian ini, siswa mengaitkan konsep yang mereka pelajari dengan pengalaman atau pengetahuan yang mereka peroleh sebelumnya. Seperti mengaitkan konsep persegi yang dapat dijumpai pada dunia nyata atau keseharian yang serupa dengan konsep tersebut. Dan dari sinilah siswa belajar mengaitkan peristiwa sehari-hari kedalam pembelajaran matematika. selain itu, dengan menggunakan media pembelajaran adobe flash siswa dapat belajar dengan melihat animasi serta visual yang menambah kemauan siswa dalam belajar.

Dari penjelasan diatas, telihat bahwa media pembelajaran adobe flash memberikan dampak positif terhadap siswa. Dan dari hasil pengamatan selama proses pembelajaran siswa sangat antusias dalam memulai pembelajaran. Media pembelajaran adobe flash memberikan siswa tampilan yang berbeda pada materi pembelajaran dengan menambahkan gambar dan warna yang menarik bagi siswa sehingga timbul rasa keingintahuan serta motivasi siswa dalam belajar.

\section{SIMPULAN DAN SARAN}

\section{A. Simpulan}

Berdasarkan hasil penelitian dapat ditarik kesimpulan bahwa hasil uji data posttest menggunakan mann whitney u-test memperoleh nilai sig. $=0,003$ yang artinya $\operatorname{sig}<0,05$, maka $H_{a}$ diterima sehingga dapat ditarik kesimpulan bahwa $\mathrm{H}_{0}$ ditolak dan $\mathrm{H}_{\mathrm{a}}$ diterima pada taraf signifikan $\alpha=$ 0,05. Dengan demikian dapat disimpulkan bahwa terdapat pengaruh media pembelajaran adobe flash terhadap kemampuan komunikasi matematis siswa di SMP Negeri 8 Langsa.

\section{B. Saran}

Adapun saran yang dapat disampaikan berdasarkan hasil penelitian yaitu :

1. Media pembelajaran adobe flash dapat digunakan guru sebagai salah satu alternatif cara untuk mengajar agarlebih menarik dengan waktu yang efisien, dan juga sebagai salah satu cara dalam meningkatkan kemampuan komunikasi matematis siswa.

2. Bagi siswa diharapkan untuk bisa berpartisipasi secara aktif dalam pembelajaran di kelas agar tujuan pembelajaran dapat tercapai dengan optimal.

3. Bagi guru, sebagai masukan diharapkan dapat mempelajari dan memahami cara pembuatan bahan ajar menggunakan adobe flash sehingga mampu menerapkan pembelajaran dengan media adobe flash dalam proses belajar dan mengajar di kelas.

\section{DAFTAR RUJUKAN}

Darkasyi, Muhammad, dkk. (2014). Peningkatan Kemampuan Komunikasi Matematis dan Motivasi Siswa dengan Pembelajaran Pendekatan Quantum Learning pada Siswa SMP Negeri 5 Lhokseumawe. Jurnal Didaktik Matematika. 1(1).

Grace Amalia A. Neolaka. (2017). Landasan Pendidikan Dasar Pengenalan Diri Sendiri Menuju Perubahan Hidup. Depok : Kencana

Husna, dkk. (2013). Peningkatan Kemampuan Pemecahan Masalah dan Komunikasi Matematis Siswa Sekolah Menengah Pertama Melalui Model Pembelajaran Kooperatif tipe ThinkPair-Share (TPS). Jurnal Peluang. 1(2):85

Ibnu Sina, dkk. Pengaruh Multimedia Interaktif dalam Pembelajaran Matematika Terhadap Kemampuan Komunikasi Matematis Siswa. Suska Journal of Mathematics Education 5(1)

Kamaliyah, dkk. (2013). Menyelesaikan Soal Matematika Model PISA Level 4. JPM IAIN Antasari, 1(1)

Muhammad Tohir. (2019). Hasil PISA Indonesia Tahun 2018 Turun Dibandingkan Tahun 2015. UNIB Situbondo: Indonesia.

Olivia Cherly Wuwung. (2020). Strategi Pembelajaran \& Kecerdasan Emosional. Surabaya: Media Pustaka.

Pane, Nursyahbany Sitorus, dkk. (2018). Analisis Kemampuan Komunikasi Matematis Siswa pada Materi Penyajian Data di Kelas VII Mts Islamiyah Medan T.P 2017/2018. AXIOM. 7(1).

Rezeki, Sri. (2018). Pemanfaatan Adobe Flash Cs6 Berbasis Problem Based Learning Pada Materi Fungsi Komposisi dan Fungsi Invers. Jurnal Pendidikan Tambusai. 2(4).

Sholeh, Muhammad dan Anisa Fatwa Sari. (2018). Proses Metakognisi Tahap Evaluation Siswa SMP dalam Menyelesaikan Soal PISA. JKPM 2(1). 
Sugiyono. (2010). Metode Penilitian kuantitatif, kualitatif dan R\&D cet.ke-19. Bandung: Alfabeta .(2013) Metode Penilitian kuantitatif, kualitatif dan R\&D cet.ke-19. Bandung: Alfabeta

Syah Putri, Zahwa dan Fibri Rakhmawati. (2018). Pengaruh Multimedia Macromedia Flash Terhadap Hasil Belajar Matematika Peserta Didik Pada Materi Pokok Persegi Panjang Dan Persegi Kelas Vii Di Mts Al-Ulum Medan T.P. 2016/2017. AXIOM. 7(1).
Unaisah. (2018). Pengembangan Media Pembelajaran Berbasis Adobe Flash Materi PrinsipDesain di SMK Negeri 1 Saptosari. Yogyakarta. HIm: 14

Widiyastuti, Nina. (2018). Pengembangan Media Pembelajaran Interaktif Menggunakan Software Adobe FlashMateri Bumi dan Alam Semesta. 32(1).

Yeni Yuniarti. (2014). Pengembangan Kemampuan Komunikasi Matematis dalam Pembelajaran Matematika di Sekolah Dasar. Eduhumaniora. Cibiru. 6(2) 